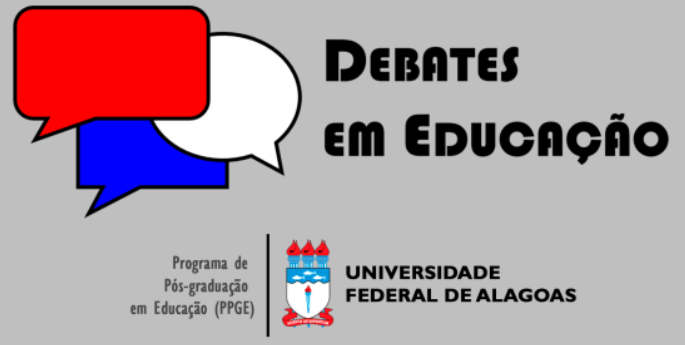

ISSN Eletrônico 2175-6600

Vol. 12 | No. 27 | Maio/Ago. | 2020

Janete Ribeiro Nhoque

9 iD

Universidade do Vale do Itajaí (UNIVALI)

jnhoque@uol.com.br

Adair de Aguiar Neitzel

9 iD

Universidade do Vale do Itajaí (UNIVALI)

neitzel@univali.br

\section{NARRATIVAS DO LEITOR DO LITERÁRIO PELO VIÉS DA ANÁLISE PROGRESSIVA DE ROLAND BARTHES}

\section{RESUMO}

Este artigo apresenta uma proposta de análise metodológica de textos narrativos em pesquisas acadêmicas que busca ampliar as possibilidades interpretativas do pesquisador, tendo como palimpsesto a análise progressiva do texto literário, proposta por Barthes ( 1999 ). O objetivo é exemplificar a utilização dessa metodologia a partir de dados construídos em uma pesquisa mais ampla, envolvendo narrativas de leitores do literário. Foi possível constatar que a utilização dessa metodologia coloca em foco o processo de escuta do pesquisado, no qual o pesquisador é um articulador, um mediador entre a narrativa e os sentidos que nela emergem. A análise progressiva da narrativa apresenta-se como outra possibilidade metodológica de pesquisas que envolvam as artes, no campo das Ciências Humanas, em especial o da Educação.

Palavras-chave: Análise progressiva. Formação de leitores. Leitor do literário. Mediação de leitura.

\section{NARRATIVES OF THE LITERARY READER THROUGH THE ROLAND BARTHES PROGRESSIVE ANALYSIS}

\begin{abstract}
This paper presents a proposal for methodological analysis of narrative texts in academic research that seeks to broaden the interpretative possibilities of the researcher, having as palimpsest the progressive analysis of the literary text, proposed by Barthes (1999). The objective is to exemplify the use of this methodology based on data built on a broader research, involving narratives of literary readers. It was found that the use of this methodology focuses on the listening process of the researched, in which the researcher is an articulator, a mediator between the narrative and the meanings that emerge in it. The progressive analysis of the narrative presents itself as another methodological possibility of research involving the arts, in the field of the Human Sciences, especially that of Education.
\end{abstract}

Keywords: Progressive analysis. Reader education. Literary reader. Reading mediation.

Submetido em: 03/08/2019

Aceito em: 07/03/2020

Publicado em: 22/06/2020

do: http://dx.doi.org/10.28998/2 I75-6600.2020v I 2n27p I05-124 


\section{INTRODUÇÃO}

Nunca the aconteceu, ao ler um livro, interromper com frequência a leitura,
não por desinteresse, mas ao contrário,
por afluxo de ideias, excitações, associações?
Numa palavra, nunca lhe aconteceu ler levantando a cabeça?

Roland Barthes

A leitura do literário é um movimento complexo que se delineia na relação que se estabelece entre texto e leitor, pois cada um se relaciona de uma forma diferente com o que lê, e essa dinâmica pode gerar excitações, associações ou ainda desinteresse, como cita Barthes (20। 2, p. 26, grifo do autor) no fragmento anterior.

O leitor, no momento de encontro com o texto literário, traz um projeto prévio de leitura nem sempre consciente, marcado por toda a intersubjetividade de encontros anteriores que o constituíram até aquele momento, recorre a ele quando lê; e quando encontra algo que o incomoda, o surpreende ou o provoca, afasta o olhar do texto em busca de sentido, de relações, de associações entre o que lê e suas outras leituras, experiências e vivências.

Instigadas por esta relação entre o leitor e o texto literário, vimos, no Grupo de Pesquisa Cultura, Escola e Educação Criadora, da Universidade do Vale do Itajaí, desenvolvendo pesquisas acerca das experiências dos leitores do literário, dentre as quais citamos Offial (20 I2), que discutiu sobre a concepção de literatura da Escola da Ponte de Portugal; Bridon (2013), que abordou sobre as competências leitoras e traçou o perfil do "leitor produtivo"; Weiss (20।6), que investigou formas de mediar o texto literário na Educação Básica; Piske (2017), que descreveu como os bolsistas do Programa Institucional de Bolsas de Iniciação à Docência (PIBID) mediavam o texto literário; Verter (2019), que explorou mediações de leitura de obras literárias selecionadas para o vestibular no Ensino Médio, visando contribuir para a formação de leitores sensíveis; e Nhoque (2019), que buscou compreender como fazer uma experiência a partir da leitura do literário repercute no leitor, amplia seus sentidos e o constitui um leitor encarnado.

Estas pesquisas apontam que a leitura do literário envolve um texto plurissignificativo que tem uma função estética e que esta é sempre provocação de sentidos e de deslocamentos no leitor, o que nos levou à necessidade de adotar, em nossas pesquisas, uma metodologia de análise de dados que se distanciasse das categorizações e ampliasse as possibilidades de sentido e de interpretação.

Buscávamos, assim, uma metodologia que considerasse como o leitor do literário se relaciona com o texto, seja no aspecto que evidencia os saberes já constituídos pela ciência, seja no aspecto que respeita a polivalência e a reversibilidade da narrativa dos sujeitos pesquisados. Uma metodologia que não simplificasse a voz do leitor e que desse lugar para os enigmas que surgem pela sua narrativa, assim como para as suas ações empíricas, um caminho que evidenciasse as percepções dos sujeitos de pesquisa. 
Chegamos, desse modo, à Análise Progressiva da Narrativa, um palimpsesto da metodologia de leitura do literário desenvolvida por Barthes (1999), a partir do conto Sarrasine, de Honoré de Balzac.

Nhoque (2019), em seu trabalho de pós-graduação stricto sensu, aplicou essa metodologia na pesquisa cientifica; e, neste artigo, a partir de uma análise documental, valemo-nos de uma releitura destes dados já publicados com o objetivo de exemplificar como a metodologia de análise desenvolvida por Barthes pode ser utilizada também na análise de narrativas construídas em pesquisas científicas. $\bigcirc$ corpus analisado trata-se da narrativa de Sofia (codinome escolhido pela entrevistada), 43 anos, formada em Direito, licencianda do curso de Letras e participante do Programa de Literatura Infanto Juvenil (PROLIJ)' e é um extrato do trabalho de Nhoque (2019).

\section{PERCUSO METODOLÓGICO}

Nhoque (2019), no trabalho de pesquisa stricto sensu, construiu os dados de sua pesquisa por meio de entrevista em um enfoque Multimétodos (GASKELL, 20 I5), com a junção de características relevantes da Entrevista Narrativa (JOVCHELOVITCH; BAUER, 20I5), a Entrevista Episódica (FLICK, 2015) e o Grupo Focal (GASKELL, 20I5). A autora optou por esse enfoque porque buscava um instrumento de coleta de dados que possibilitasse a escuta de como a leitura do literário repercutia em cada um dos leitores e o compartilhamento de experiências entre eles.

Para provocar os sujeitos da pesquisa e dar início às discussões, a autora selecionou um fragmento de quinze minutos do filme Minhas tardes com Margueritte, de Jean Becker (ao clicar no título do filme ou acessar pelo celular o QRCode ${ }^{2}$, direcionará para o fragmento utilizado no encontro). Dessas discussões, foram geradas as narrativas e, aqui,

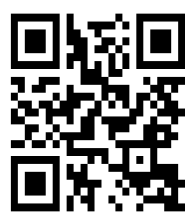
apresentamos e analisamos a narrativa de Sofia.

\section{I Análise progressiva de Roland Barthes}

Na interpretação de um texto plural, segundo Barthes ( 1999 ), o autor constrói, intencionalmente, pontos de fuga para que o leitor possa entrar no seu jogo de significações. Para Barthes, o texto possui vozes que são permutáveis, reversíveis e que não estão presas ao tempo e vozes que são legíveis, que

\footnotetext{
' Fundado em 1997, na Universidade da Região de Joinville (UNIVILLE), segundo o site de divulgação do programa, envolve atividades de ensino, pesquisa e extensão na universidade e é "[...] responsável pela promoção, crítica e circulação da Literatura Infantil Juvenil na região norte do Estado de Santa Catarina", contribuindo "[...] social e culturalmente com a comunidade acadêmica e não-acadêmica tornando-se um centro de referência na área em que atua" (BLOG DO PROLIJ, 20 I7, n.p.).

2 "QRCode (sigla do inglês Quick Response) é um código de barras bidimensional que pode ser facilmente escaneado usando a maioria dos telefones celulares equipados com câmera." Disponível em: https://pt.wikipedia.org/wiki/C\%C3\%B3digo_QR. Acesso em: 15 jan. 2018.
} 
seguem uma lógico temporal. A cada uma dessas vozes da narrativa, Barthes representa por um código, que, na pesquisa de Nhoque (20 I9), são representadas por símbolos (Figura I), os quais utilizaremos para análise do depoimento de Sofia.

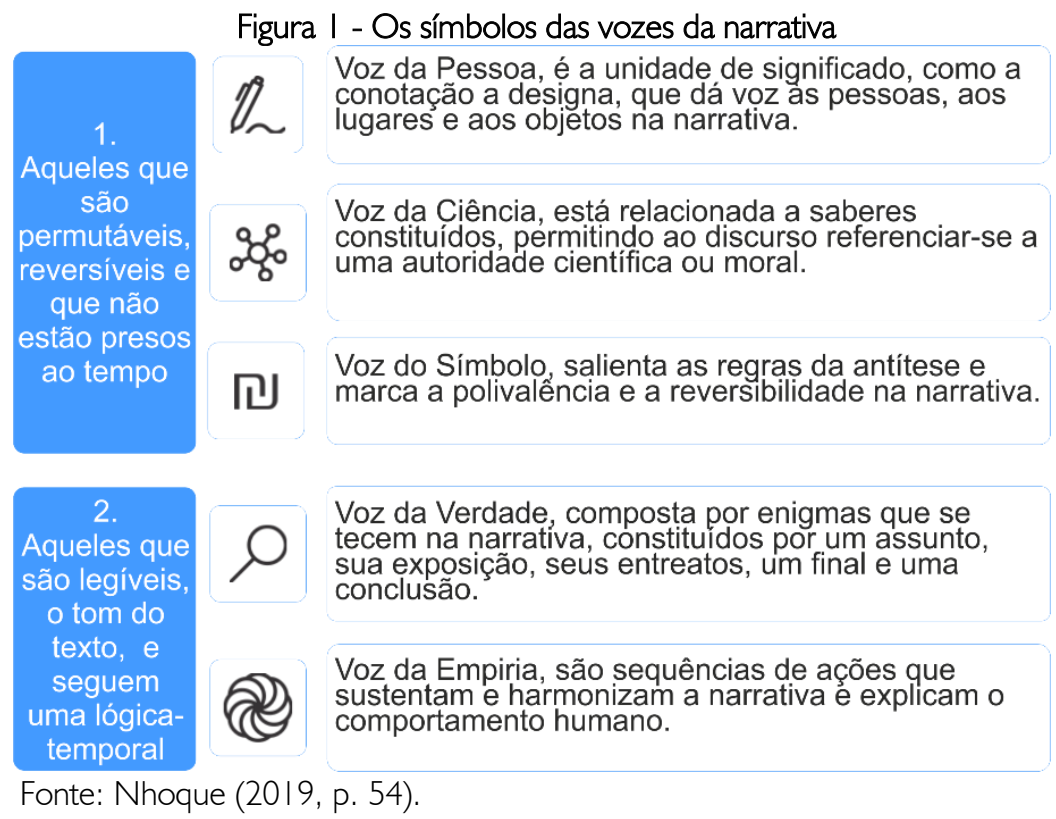

Uma análise progressiva é constituída de um texto tutor, aquele formado pela transcrição dos dados coletados na pesquisa; neste caso, a narrativa de Sophia, que buscamos interpretá-lo de forma a apreciar sua pluralidade de sentidos e teorizar sobre as vozes da narrativa. Essas vozes são perspectivas de citações, marcas, fragmentos do lido, visto, feito ou vivido que emergem na narrativa. É no entrelaçamento entre essas vozes que a narrativa vai se constituindo como texto. Essas vozes da narrativa ora dão brilho, tom, ora a tecem e a sustentam.

Partindo do texto tutor, o primeiro movimento da análise consistiu em estelar o texto, isto é, decompô-lo em pequenos blocos de significação (BARTHES, 1999), as lexias, unidades de leitura. Neste artigo, elas foram enumeradas de acordo com a ordem em que foram se constituindo. $O$ texto assim organizado denominamos de texto estelado, isto é, um texto que, por sua forma, lembra um céu "[...] simultaneamente plano e profundo, liso, sem margens nem pontos de referência" (BARTHES, 1999, p. 18).

O segundo movimento da análise foi estilhaçar esse texto estelado; desse modo, após a leitura de cada lexia, afirmamos sua pluralidade, buscando encontrar os sentidos, nomeando-os, renomeando-os, por meio de um ou mais das cinco vozes da narrativa. Destacamos que são as marcas da nossa escuta, outro leitor poderá estelar e estilhaçar de outra maneira, constituindo, assim, uma outra sequência de vozes e sentidos. 
No desenrolar desses movimentos, dois outros ocorrem simultaneamente: a releitura e a reversibilidade. Entendemos releitura também como um deslizar (BARTHES, 1999) pela pluralidade do texto, não de forma linear, relendo-o em busca de outros textos que transportava, mas como possibilidade de perceber nuanças que abriam para a multiplicidade de sentidos, o que era latente, aquilo que ficava nas entrelinhas, nas dobras do dito, interpretando-o.

Juntamente à releitura, outro movimento entrou em cena, a reversibilidade (BARTHES, 1999), isto é, o movimento que realizamos durante a leitura e a releitura em busca de significados. Na leitura reversível, o leitor não se prende no enredo do texto, mas, sim, realiza diversos movimentos para interpretar sua tessitura.

Esse texto-leitura (BARTHES, 20I2) é denominado texto único, último movimento da metodologia barthesiana de análise, caracterizado como o destino de uma análise progressivamente descrita. É único não por se tratar de um modelo, mas por ser uma rede de entradas no texto, dentre muitas outras possíveis e elaborado a partir das teorias sobre as vozes e pontos de fugas que surgem no desenrolar da análise. É esse texto-único que apresentamos a seguir.

\section{A ANÁLISE PROGRESSIVA DA NARRATIVA: SOFIA, A LEITORA DO LITERÁRIO QUE BUSCA O ESTAR-JUNTO}

Nhoque (2019), ao reunir três leitores para uma entrevista, propôs uma provocação por meio de um fragmento do filme Minhas tardes com Marguerite para, segundo a pesquisadora, deflagrar questões que a permitiriam aventar hipóteses sobre a história de cada leitor. Sofia compartilhou qual a parte do filme identificou-se com sua história de leitora.

(I) [...] acho que pela vontade de aprender a ler, assim, que ele tem, ele tem essa vontade. (NHOQUE, 2019, p. 88).

A primeira questão que nos colocamos diante dessa afirmação de Sofia é: Por que ela se identifica com o personagem pela vontade de ler? [ OEnigma I: (assunto) o que levou Sofia a ler?].

(2) [...] mas, ao mesmo tempo, ele tem alguns bloqueios né, ele não sabe como... que vem lá da infância... não sabe como contornar isso [...]. (NHOQUE, 20|9, p. 89).

Sofia identifica que a personagem do filme possui alguns "bloqueios" que vêm da infância. Por que ela escolheu a infância da personagem para apontar esses bloqueios? Ela destaca que são bloqueios que ele não sabe contornar e demonstra curiosidade em descobrir que bloqueios foram esses. Por que na infância? [ Enigma I: (resposta suspensa): Bloqueios]. 
Cada sujeito é tocado de uma maneira pelo que está a sua volta. No caso das artes, como o cinema ou a literatura, talvez o que nos atraia se estabelece por aquilo que Manguel (2005, p. 25) chama de "vínculo de coincidências." Os movimentos de identificação que traçamos entre nós e as coisas envolvem a maneira como as compreendemos e as relações que estabelecemos entre elas. Estas são múltiplas e referem-se à cada sujeito e aos saberes adquiridos no decorrer de sua vida. Se entendermos assim, quais vínculos de coincidências estariam envolvidos entre Sofia e o fragmento do filme que a levou a expressar os termos "vontade de aprender" e "bloqueios"?

(3) [...] então, essa vontade me lembra quando eu era pequena, que eu tinha muita vontade de aprender a ler. (NHOQUE, 2019, p. 89).

A questão começa a ser esclarecida quando Sofia ativa sua memória e relembra quando era pequena [ơ⿱宀ః Cronológica: infância]. Ela se identifica com a personagem do filme na relação este construiu com a leitura na infância.

Sofia sentia vontade de aprender a ler [ $\bigcirc$ Enigma I: (explicação): vontade de aprender]. Parecenos que o gosto pela leitura, em Sofia, surge nesse período. Petit (20 I 2) considera a infância um momento importante para que a criança adquira o gosto pela leitura, pois é, nesse momento, que estamos mais abertos a "[...] descobertas das palavras, das histórias, dos livros ou dos objetos amados" (PETIT, 20 I 2, p. 52) que nos são apresentados e, também, o momento para sermos despertados para o sensível, o intelectual e o estético. Nesse momento de grandes descobertas, ficam, em nossas memórias afetivas, lembranças que são suscitadas quando somos provocados, como ocorreu com Sofia. É também o início de sua vida escolar, quando passa a ser aceita em um novo grupo, de participar e compartilhar com o outro [ 2 ser aceito].

(4) [...] porque eu via as pessoas lendo e tinha essa curiosidade. (NHOQUE, 20I 9, p. 90).

Sofia tinha vontade de aprender a ler porque via as pessoas ao seu redor lendo e isso lhe provocava curiosidade [ OEnigma I: (formulação) curiosidade]. Contudo, ela não nos esclarece por que ficava curiosa e nem quem seriam as pessoas que liam, nem o que liam. Percebemos que o enigma continua. Sofia adia seu desfecho e aponta-nos outras inquietações.

A afirmação de que via as pessoas lendo e tinha curiosidade permite-nos compreender que a leitora de hoje surgiu lá na infância pelo desejo em atender a uma curiosidade interna: $\bigcirc$ que será que aquelas pessoas liam?

Ler em público, mostrar interesse pela leitura são atos que instigam e impulsionam outros leitores [खe "ler": I: observar pessoas lendo]. A declaração de Sofia confirma que a convivência com pessoas leitoras contribui para a formação de um leitor, instiga o outro a ler, desperta a curiosidade pelo livro. 
Temos aqui pistas de que mediadores de leitura podem muito, não só quando sugerem livros, leem, contam histórias, mas também quando simplesmente se mostram leitores.

\section{I Mediar}

Petit (2012, p. 52) trata dos "[...] mediadores que impelem aqueles que encontram" em seu caminho para a leitura. Segundo a autora, o gosto pela leitura inicia-se na infância e, por meio de encontros da criança com um mediador de leitura, que pode ser um parente, um bibliotecário, um professor, um vizinho, "[...] alguém que manifesta à criança, ao adolescente, e também ao adulto, uma disponibilidade, uma recepção, uma presença positiva e o considera como sujeito" (PETIT, 20।2, p. 48).

Como podemos notar, mediar a leitura, para Petit, envolve uma ação (disponibilidade, recepção), mas também um sentimento perante o leitor que não só qualifica a relação (presença positiva), como também com o leitor, ao considerá-lo como sujeito, isto é, alguém que age, interage com o mediador.

A mediação ocorreu para Sofia de forma indireta, pela observação da ação leitora de um adulto, já que o ato de ler do mediador provocou o olhar curioso da menina Sofia.

(5) [...] e eu tive dificuldade de aprender a ler... eu fui uma criança que aprendeu a ler muito tarde assim, né... depois de todo mundo. (NHOQUE, 2019, p. 91).

O enigma vai se revelando, o "bloqueio" ao qual Sofia se refere é a dificuldade de aprender a ler, ler depois que os outros já aprenderam [ $\bigcirc$ Enigma I: (explicação) vários motivadores], questão muito evidente no fragmento do filme abordado anteriormente. A dificuldade em aprender a ler é uma realidade em muitas escolas brasileiras, largamente apontada nas avaliações externas pelas quais passam as crianças em idade escolar.

Como podemos perceber pela narrativa de Sofia, essa imagem da criança que não lia no mesmo tempo que as outras ficou-lhe marcada na vida, pois, mesmo depois de tantos anos, é uma das suas primeiras memórias afetivas quando trata sobre como aprendeu a ler - e, possivelmente, é a de outras tantas crianças que passam pela mesma dificuldade. Contudo, isso não a impediu de se tornar a leitora do literário que é hoje, o que nos indica que a dificuldade de aprendizagem é o que é, uma dificuldade, que pode ser superada do decorrer da vida da criança, não sendo um impeditivo para que se torne uma leitora do literário mais tarde.

(6) Então, isso, me identifiquei com ele: essa dificuldade e ao mesmo tempo essa vontade. (NHOQUE, 2019, p. 91).

Há um paradoxo que envolveu a relação de Sofia com a leitura na infância: seu desejo de estarjunto àqueles que liam e a dificuldade em aprender que a leitura envolvia ["ФAntítese: saber ler/dificuldade 
de aprender]. $\bigcirc$ desejo de ler foi alimentado pela presença constante dos leitores a sua volta e a dificuldade em aprender a ler não foi impeditivo para alcançar este desejo, o que nos convida a pensar no desejo como elemento motivador para que a leitura se efetive. Assim, Sofia revela-nos que, na infância, lia para estar-junto ao outro. E a Sofia adulta? $\bigcirc$ que a leva as leituras? [ $\bigcirc$ Enigma 7: (assunto): o que move Sofia a ler].

(7) Hoje em dia, é lendo artigos especializados mesmo assim, alguma coisa do jornal, de algum colunista indicando sobre literatura, também programa na televisão, blogs sempre tem indicações ótimas. (NHOQUE, 2019, p. 99).

Sofia divide a maneira como busca fazer uma experiência com a leitura do literário em dois momentos "hoje em dia" e uma outra que ela nos oculta [ö̊̊ Cronológica]. Suas referências para ler estão em instituições (revistas especializadas, jornais, TV) e em espaços não formais (blogs), aos quais reconhece autoridade sobre o tema [ä̊̊̊. Cultural: espaços de circulação da literatura].

(8) [...] mas muita também por indicação de pessoas que eu admiro assim, por ter uma personalidade que fala de determinado livro, eu admiro, eu vou atrás do artista. (NHOQUE, 2019, p. 99).

A influência de uma autoridade reconhecida por Sofia na escolha de suas leituras é significativa [ admiração]. Essa autoridade vem da admiração que tem por algumas pessoas, que, sendo leitores, fazem com que ela se movimente em busca das leituras "recomendadas" [ $\rho$ Enigma 7: (explicação): recomendação]. Novas formas de mediação do texto literário aparecem em sua narrativa, valorizando novamente as mãos daqueles mediadores que introduzem os leitores no universo leitor.

(9) Eu cheguei na Clarice Lispector por causa do Renato Russo, de quem eu era fã na adolescência. Ele falou bem, daí eu fui atrás dessa mulher. "Quem é essa que ele fala tão bem?"; então, é por aí. (NHOQUE, 2019, p. 100).

Sofia aponta-nos aqui outra forma de mediação, uma mediação não intencional e nem direta. Ela

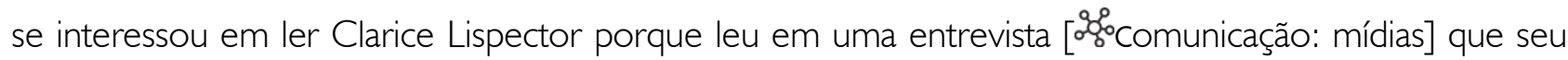
ídolo Renato Russo afirmava ler Clarice - e isso a fez procurar a autora [ $\bigcirc$ Enigma 7: (explicação): um ídolo]. Movimento semelhante é descrito por Barthes (1999) quando nos explica por que decidiu ler o texto Sarrasine, de Balzac. Segundo o autor, seu interesse deu-se porque leu um autor que afirmara ler Balzac por uma citação de outro autor. Ele completa: "[...] encontrava-me assim incluído neste transporte" (BARTHES, 1999, p. 20, grifo do autor), uma leitura que en-caminha seus leitores para outras leituras (GADAMER, 2016). Assim sendo, o mediador de leitura nem sempre é uma pessoa, pode ser um objeto propositor. Para Sofia, esse objeto propositor foi uma entrevista, para Barthes o texto Sarrasine. 


\subsection{0 interdito}

Sofia nos narra como encontrou o "livro proibido" e com o interdito foi crescendo seu desejo pelo texto literário:

( 10$)$ E tem isso do proibido também. Na minha adolescência, eu li muita coisa que era proibida. Meu pai era sócio do Círculo do Livro, daí tinha aquela estante cheia, que era maravilhosa. Ele dizia: "Isso aqui não pode ler". Tinha lá Stephen King e livro de terror e eu lia escondida, né, morrendo de medo, porque era proibido. Tinha Henry Miller, aprendi bastante coisa. Nexus, Plexus e Sexus, né, porque era proibida, não podia ler. (NHOQUE, 2019, p. 100).

A leitura dita "proibida" na adolescência [ơ̊̆. Cronológica], imposta pela autoridade de seu pai, o

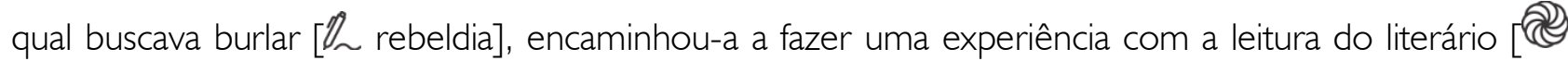
"ler" 2: ler escondido]. Manguel (2005), que nos leva a uma viagem pela história da leitura, narra que muitos livros foram proibidos e muitas fogueiras acesas para impedir que fossem lidos. Essas censuras buscavam limitar as possibilidades do leitor, mas, com Sofia, a tentativa de cerceamento teve um efeito contrário, instigou-a a ler [DAntítese: proibição/desobediência].

A narrativa de Sofia traz-nos outras três informações importantes: a estante "maravilhosa" cheia de livros adquiridos por meio do "Círculo do Livro" [o̊\%ిం Cultural, os livros comprados pelo correio], apontando para um pai leitor; a facilidade de acesso a alguns títulos pelos quais afirma ter aprendido; e a busca pela compreensão de anseios da adolescência [ơğ Literatura erótica]. Há também um impulso lúdico que se revela pelo jogo de esconde/revela entre a adolescente e aquele que the proibia suas possibilidades de leitura.

( I I) Então, por aí também. A melhor coisa para um adolescente ler é dizer "é proibido". "Esse aqui não pode, esse é muito forte para você". E realmente tem que ter alguma coisa forte, porque senão adolescente vai largar, né, mas, por aí assim, também. (NHOQUE, 2019, p. 101).

A experiência da adolescente que gostava de ler livros proibidos repercute na leitora adulta: a leitura para adolescentes "tem que ter alguma coisa forte". Sofia dá-nos um exemplo de como a leitura do literário colabora na constituição do leitor e de suas crenças [ $\bigcirc$ Enigma 7: (explicação): a leitura proibida]. Sua experiência exitosa, pois, hoje, se considera uma leitora, a faz acreditar que provocar o leitor adolescente com "coisas fortes" é um caminho para ele não deixar de ler. A provocação pode desencadear o desejo pela leitura e abrir possibilidades leitoras.

Quando perguntada sobre os livros que marcaram sua infância de leitora, Sofia lembra-se do livro que recebeu logo que aprendeu a ler:

(I2) Lembro... lembro porque ganhei logo que eu aprendi a ler. Como eu disse, eu demorei, quando eu finalmente aprendi a ler, foi um máximo em casa. E o meu pai trouxe para casa o Pequeno Príncipe, e a gente começou a ler juntos assim, lembro que a gente sentava e ele lia 
comigo... ele ia lendo e ele ia me ajudando e me explicando também, porque era muito novo para mim assim, entender aquela linguagem. (NHOQUE, 2019, p. 107).

O desejo de compartilhar a leitura e ser aceita no círculo de leitores familiares acende em Sofia a chama leitora. Ler é percebido como um ritual de passagem para entrar em um grupo desejado: aqueles que liam. Esse desejo a leva à superação das dificuldades para aprender a ler e o livro recebido é a chancela

que revela o reconhecimento dos familiares [ $\bigcirc$ Enigma I: (conclusão) estar-junto]. É esse o elemento afetual que reverbera de suas lembranças: o prazer de estar-junto ao pai para ler [ $\mathcal{Z}$ felicidade]. $\bigcirc$ pai de Sofia atuou como um mediador de leitura que acolhe o leitor iniciante, apoia-o em suas dificuldades, caminha junto, dando-lhe incentivo para que continue e deixa-o caminhar sozinho apostando na sua autonomia.

\subsection{Autonomia}

(13) E até que ele sentiu, eu acho, não sei se foi isso ou ele sentiu que eu engrenei de alguma forma na leitura, porque ele disse: "Daqui para frente, é contigo", "não, mas eu quero saber o resto da história", "não, mas se tu quer saber mesmo o final da história, é contigo". (NHOQUE, 2019, p. 107).

A autonomia leitora passa pela aquisição de competências leitoras, e o primeiro passo para essa autonomia é o reconhecimento dos signos alfabéticos. Uma vez reconhecidos, os signos podem ser portas para variados mundos. A leitora adulta busca compreender o que a leitora da infância não entendia, o pai não a estava abandonando, mas, sim, instigando-a a continuar, a buscar por si os sentidos do texto [ $\mathbb{Z}$ estar só]. Petit (2012, p. 76) aponta-nos que a leitura "[...] é uma verdadeira abertura para um outro lugar, onde o devaneio, e, portanto, o pensamento, a lembrança, a imaginação de um futuro tornam-se possível". Foi a possibilidade de adentar esse lugar, no nosso entender, que o pai de Sofia lhe ofereceu ao dizer "é contigo".

(14) [...] e foi o primeiro livro que eu li assim. Foi o Pequeno Príncipe... chorava, né... aquele final meio que me marcou bastante. Até não trouxe ele... sai na corrida de casa, mas eu tenho até hoje esse livro. Tá todo..., tá todo assim... me marcou bastante. (NHOQUE, 2019, p. 107).

Sofia adentrou aquele lugar e revela-nos como o leitor pode se envolver com as leituras que faz [ V sensibilidade]. Aquela primeira experiência com a leitura do literário repercute em Sofia, que traz consigo ainda o livro que fez parte desse encontro. O livro como objeto de desejo que representa a marca de mudança de alguém que queria muito saber o que os outros liam (4), esforçou-se para conseguir a ler e a obter o reconhecimento daqueles que amava (12). Ser aceito pelo grupo e dele ter seu reconhecimento é parte daquilo que nos torna humanos. A narrativa de Sofia aponta a leitura do literário como uma possibilidade de aproximação afetiva entre as pessoas, o acolhimento e a inclusão a partir da 
leitura, que deixa de ser uma relação apenas do leitor com o livro, mas do sujeito leitor com sua comunidade.

\subsection{Repertórios}

( 15) Depois disso, aí era muito gibi. Meu pai viajava, ele era representante comercial, a gente morava em Tubarão, uma cidade pequena. Quando ele ia pra São Paulo, ele sempre dava um jeito de passar na livraria e de trazer ou o "Asterix", que a gente estava conversando hoje, ou, então, "As Aventuras do Tim-Tim". Então, isso me marcou muito assim... como eu disse, ele assinante do Círculo do Livro, que não tinha nenhuma linha para criança, mas a gente ia pegando assim o que tinha. (NHOQUE, 2019, p. 108).

A falta de acesso da família ao gênero literatura infantil é registrado por Sofia, e as histórias em quadrinhos - que eram trazidas pelo pai viajante [\%ి̊ Geográfico: Tubarão/SC e São Paulo/SP] - surgem como uma opção de leitura diante dessa dificuldade. As leituras de gibi da infância repercutem nas conversas da leitora adulta [@ "ler"3: conversar com o outro sobre suas leituras de infância], além da presença marcante do pai que era um leitor com "estante cheia" (10) de livros, que lia junto a ela, explicando o que não entendia (12) e que Ihe trazia gibis quando voltava de viagem [ 2 admiração]. Sofia mostra-se leitora de clássicos, como $O$ pequeno príncipe e de quadrinhos. Ambos os gêneros literários foram responsáveis pela entrada de Sofia no mundo da leitura.

(16) E daí, eu acho que eu estava na quarta série, quando surgiu a Coleção Vagalume, que daí também foi outra descoberta, ali "O caso da Borboleta Atíria", "Um cadáver ouve rádio", tudo isso eu li na época assim. Foi muito bom. (NHOQUE, 2019, p. 108).

A literatura infanto-juvenil é também citada por Sofia que se recorda de uma coleção de livros que conheceu na escola [ơ⿱宀 Literatura: Coleção Vagalume] e que Ihe trouxe prazer em ler, e ela usa uma palavra interessante para descrever esse movimento de tornar-se leitora: "descoberta". No entanto, descoberta de quê? [ $\bigcirc$ Enigma 7: (resposta suspensa): $\bigcirc$ que Sofia descobre com a leitura?].

(17) [...] a minha mãe não gostava de ler, ela achava que as pessoas que liam eram esquisitas, ela dizia que meu pai era uma pessoa muito encucada e que ela não queria que virássemos pessoas encucadas, eu e meu irmão, então, ela era sempre aquela que, né...mas, curiosamente, ela me presenteou uma vez com uma coleção de livros que era de contos de fadas [...]. (NHOQUE, 2019, p. 108).

Sofia mostra-se intrigada com a maneira como a mãe percebe a leitura, pois, enquanto descreve uma mãe que não gosta de ler, diz que foi presenteada pela mãe com uma coleção de livros [] Paradoxo: mãe diz não gostar de ler/ presenteia com livros]. Na sua família, Sofia convive com um pai leitor e uma mãe que não gosta de ler e se preocupa que os filhos se tornem leitores [ㄴ Antítese: pai leitor/mãe não leitora]. Além disso, a mãe preocupada compra livros para a filha de presente [ Paradoxo: não querer que a filha seja leitora/comprar livros para a filha] ampliando o repertório da filha, oferecendo a ela contos 
de fadas que se somam ao Pequeno príncipe, às histórias em quadrinhos e às obras da Coleção Vagalume. O paradoxo indica que a preocupação da mãe se justifica porque ela não quer ver seus filhos desajustados (Sofia utiliza os termos "encucados" e "excluídos"), o que revela que a mãe se preocupa com uma questão social, quer garantir que seus filhos sejam aceitos na sociedade [ [å̊̊. Relações sociais: ser aceito].

(I8) [...] também amei aquela coleção, mas eu gostava por causa dos contos de Christian Andersen e Perrault, que, para mim, eram os mais tocantes assim; então, a pequena sereia foi uma coisa que eu internalizei, né, que hoje eu faço terapia para tirar a pequena sereia de dentro de mim, porque ela é muito submissa, eu acho... mas é isso, assim, me formou bastante, me marcou demais. (NHOQUE, 2019, p. 109).

Sofia revela-nos a leitura que toca, que ressoa nas emoções, nos sentimentos [ $\mathcal{Z}$ sensibilidade] da criança que, na infância, leu e repercute na adulta que hoje pensa sobre a leitura e sobre seu lugar no mundo. Sofia tem consciência de que a leitura do literário, quando vivida como experiência, quando faz parte da vida do leitor, provoca marcas, movimenta-o.

Eco (2003) fala-nos dos movimentos de identificação e de projeção que ocorrem com o leitor na sua relação com a leitura. O leitor fantasia, vê-se em situações imaginárias que ecoam em reações físicas que o fazem sentir aquilo que a personagem sente, como ocorre com Dom Quixote, que se mostra encantado com o mundo dos livros e perde a referência na realidade.

Entretanto, o leitor não pode ficar preso às "suas próprias alucinações" (ECO, 2003, p. I 5) ou àquelas que são elaboradas para enquadrá-lo. Os contos de fada, pontua-nos Eco, trazem um apelo de manutenção da tradição, da cultura e da moral de uma sociedade. Sofia denota isso ao reconhecer que esse tipo de leitura a marcou, foi-lhe interiorizado [Q submissão], e a leitora, agora adulta, busca desmitificá-lo [@ "ler” 4: desconstrução]. Contudo, esses contos, há de destacarmos, também permitem trabalhar conflitos internos ou da convivência cotidiana mantendo certa distância deles (PETIT, 20I2).

\subsection{Leitura partilhada}

Quando perguntada se compartilhava leituras com alguém, Sofia nos respondeu:

(19) Eu tenho. Estou realizada no curso de Letras porque eu encontro várias pessoas para compartilhar. Nos outros círculos, assim, meus, não é muito comum não. Mas, mesmo no curso de Letras, existem muitas pessoas que não gostam muito de ler. Eu acho isso muito chato assim. "Eu vim aqui para compartilhar, mas ainda tem gente que não gosta". (NHOQUE, 20 |9, p. I | 2).

Novamente Sofia traz à baila a importância de compartilhar leituras, de dialogar com os pares. Ela encontra no curso de Letras pessoas para dividir leituras, já que no seu círculo de amigos não é comum. Além disso, causa-lhe estranheza encontrar não leitores em um curso que a leitura é parte do currículo [ ص Paradoxo: não leitores/formadores de leitores]. No entanto, esse fato não é incomum. As pesquisas de Octávio (2014) e Almeida (2016) apontam como dificuldade na formação do aluno leitor ou na atuação 
do professor formador a presença de professores não leitores. Ou, ainda, pesquisas como as de Todorov (20 I0) que sinalizam como a literatura está em perigo por ser mediada nas escolas de forma inadequada.

(20) [... mas assim, eu adoro trabalhar com a Alice, porque a gente, o dia inteiro, troca figurinha. A Alice vem com as referências dela. Ela escuta as minhas. Aí é bacana por conta disso. (NHOQUE, 2019, p. II2).

Ao enfatizar a necessidade de trocas leitoras, o que inclui a ampliação de referências bibliográficas, Sofia revela que essas trocas também são marcadas pela escuta do outro [@ "ler" 5: ouvir o outro]. Tratase da renúncia defendida por Heidegger (20l I), no encontro com o outro, renúncia da imposição de nossa maneira de interpretar para abrir-se à alteridade e, assim, compartilhar leituras, afetos, sentimentos. Sofia revela-nos que o "trocar figurinha" não é ter as mesmas ideias. O que enriquece é a diversidade, é aquilo que o outro traz de diferente e que só nos é desvelado se o ouvirmos [ 2 Renúncia]. Petit (2012, p. I l0) considera a possibilidade de "uma educação dos sentimentos", esses momentos de encontro de alteridades, além do reconhecimento de si que esses encontros propiciam.

(2I) E na minha infância, eu tive uma amiga, uma amiga só, durante toda a infância, que gostava de ler e a gente tinha essa troca assim. Foi quando eu morei em outra cidade durante um ano só. Então, também não foi um período muito longo. Mas ela adorava ir na minha casa também pegar os livros que eram do meu pai e daí ela levava para o pai dela para o pai dela dizer se podia ler ou não e ela me emprestava os dela assim, então, eu li muita coisa bacana por conta dela, daí sim era uma coisa mais voltada para aquela faixa etária. (NHOQUE, 2019, p. II2).

Novamente surge na fala de Sofia a responsabilidade do mediador de leitura na sua formação leitora. Compartilhar leituras, para Sofia, foi também dividir interesses, constituir vínculos, conhecer os hábitos e os valores de outra família [ $\mathcal{Z}$ compartilhar]. Ela também nos revela um hábito que não era só de sua família, a censura às leituras "inadequadas à idade" [o̊g̊ Cultural: hábitos familiares]. E, por meio de sua narrativa, identificamos novamente como o interdito não a afastou da leitura; ao contrário, a instigou.

(22) Então, tinha uns livros do J. M. Simons, tinha o "Ônibus do tamanho do mundo", "É proibido chorar". "Poliano", eu li por conta dela assim. Foi nessa época assim, depois disso, para compartilhar leitura com alguém, acho que só na faculdade. (NHOQUE, 2019, p. I13).

Sofia passa a conhecer outras referências a partir da leitura compartilhada com a amiga de infância [o̊gిం Literatura: J. M. Simons], que medeia seu encontro com outros livros, mas ela também revela a dificuldade em encontrar outros leitores para compartilhar suas leituras.

A leitora foi questionada sobre como ela via o leitor. Ele é um solitário ao ler? Para Sofia:

(23) Eu acho que não deveria ser. (NHOQUE, 20।9, p. I|4).

Sofia parece ter dúvidas se a leitura é ou não um ato solitário:

(24) Eu acho que não deveria ser tão solitário assim. Eu sinto muita necessidade de conversar com alguém quando eu estou lendo determinados livros. Já abandonei leituras porque não estava 
dando conta, não tinha certeza se estava entendendo, e eu gostaria que alguém estivesse lendo junto assim. (NHOQUE, 2019, p. 115).

Repercute em Sofia aquele desejo de infância, o querer estar-junto, que parece ser um elemento afetual que está encarnado nela. A presença do outro para a troca de ideias, para a partilha é uma necessidade desta leitora não para ter somente alguém que a escuta, mas alguém que a orienta, que sugere, que discute o lido.

\subsection{Desassossego}

A entrada no texto nem sempre é fácil, e com a ajuda de um mediador de leitura pode-se perfurálo com mais intensidade ou ainda conseguir entrar no jogo do texto, participar da montagem oferecida pelo autor. Aquele desejo de que seu pai permanecesse com ela na leitura do primeiro livro (I3) também repercute quando opina sobre a leitura ser, ou não, solitária, pois expressa uma necessidade de alguém que the ajude [0 companhia].

(25) Então, assim, é solitário, me preenche, mas algumas coisas... por exemplo, "Os Irmãos Karamázov" é um livro que eu... não é a dificuldade em si da leitura, mas porque eu enfrento partes minhas ali naquela leitura que eu precisaria de um outro para mediar isso. (NHOQUE, 2019, p. II5).

que Sofia nos revela é que a mediação de leitura quando se dá pela escuta do outro pode ampliar as possibilidades de repercussão da obra, a forma sensível e emotiva de relacionar-se com o texto. A leitora criança chorou ao ler O pequeno príncipe e isso a marcou ( I4); a leitora adulta encontra uma nova

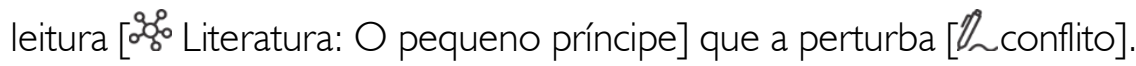

(26) Eu me vejo ali naqueles personagens... descubro coisas a meu respeito, é como se eu estivesse, sabe quando você assiste a um filme de terror e você precisa de alguém do lado para segurar a mão? Então, há algumas leituras que me provocam isso. Então, é solitário, ok. Mas algumas não deveriam ser. Algumas deveriam ser... fazer acompanhado. (NHOQUE, 2019, p. |16).

Sofia insiste na necessidade do estar acompanhada na leitura para que o texto seja perfurado, para que a leitura seja um encontro, para que os deslocamentos propostos pelo autor sejam ressignificados, para que o jogo entre obra e leitor se estabeleça. Sofia aponta que algumas leituras colocam o leitor em desassossego, pois fazem com que este se questione sobre sua identidade pessoal, mas também revela uma possibilidade de o leitor entrar no texto, pela via das emoções. Quando perguntada se sentia dificuldades com um texto como os Irmãos Karamázov e por quê, Sofia respondeu: 
Sofia trata dos entraves pessoais que barram a leitura de determinadas obras. $\bigcirc$ que a impede de atender ao impulso lúdico, de se estesiar? Ela continua a enfatizar a necessidade do mediador para vencer os entraves de mergulho em determinadas obras. Como Sofia percebe esse tipo de leitura provocativa? Como ela enfrenta o desafio proposto ao leitor de um texto plural?

(28) [...] provavelmente, um livro que me desafia é um livro que eu tento vencer assim. Então...eu não estou entendendo o que o autor está falando. Por exemplo, eu não estou entendendo uma metáfora, uma referência, aí eu vou buscar resenhas, estudos feitos a respeito desse livro, para tentar entender o que está acontecendo ali. Aí, eu sinto que estou pegando o jeito do escritor e vou em frente assim... mas, em outras, é como te disse, são dificuldades minhas mesmo, que eu me vejo. (NHOQUE, 2019, p. 116).

As relações que o leitor trava com o texto são múltiplas, como nos mostra Sofia. Há uma tensão que se estabelece entre ambos na busca de compreensão do jogo organizado pelo autor, e nem sempre Sofia consegue interagir com a leitura, e esse fato a incomoda. $O$ leitor do literário busca formas de entrar no texto, identifica os pontos de fuga, busca a mediação em outros textos, mas há a possibilidade de ficar preso em algumas de suas vozes, como emocionalmente ocorreu com Sofia [Z ¿ilusão].

\subsection{O livro de cabeceira}

Ao longo de nossa caminhada como leitores, deparamo-nos com várias obras e algumas nos afetam mais do que outras, com algumas mostramos ter mais intimidade que com outras. Para Sofia, não há um livro que lhe marcou, mas uma autora:

(29) Então, eu até coloquei no questionário, eu não tenho o livro, eu acho que tenho mais o autor, a escritora, que é a Clarice Lispector, e aí eu até coloquei dois livros dela que eu gosto bastante. Não foi o que eu trouxe, porque o que eu trouxe foi justamente o primeiro livro que eu peguei dela nas mãos e, então assim, é o escritor. (NHOQUE, 2019, p. 123).

Sofia revela-nos seu gosto literário [oిః̊ి. Literatura: Clarice Lispector] e passa a narrar como chegou até ela:

(30) Eu conheci Clarice Lispector não pelos romances, eu entrei pelas crônicas, que esse livro é um livro de crônicas, e, depois, eu passei para os contos, assim. E a Clarice romancista, ela me desafia, para mim é mais difícil, a Clarice... dos romances dela, eu li pouca coisa assim, "Uma Aprendizagem" ou o "Livro dos Prazeres", eu morro de paixão. (NHOQUE, 20।9, p. 124).

E cita dois livros que conhece [oి Literatura: Uma Aprendizagem e Livro dos Prazeres], reverberando sua paixão pela autora [ $\rho$ Enigma 7: (explicação): paixão].

(3I) Mas esse foi um livro que, então, eu lendo uma entrevista do Renato Russo, ele falou da tal da Clarice Lispector, e eu daí em seguida, vim morar em Joinville, estava no primeiro ano do segundo grau, era segundo grau na época e eu entrei no sebo aqui de Joinville, que era uma coisa que não tinha em Tubarão, que eu achava fantástica também, e aí eu dei de cara com esse livro e levei para casa, devia ser um real, dois reais... eu lembro até hoje. (NHOQUE, 2019, p. 124). 
Novamente, Sofia revela a força do mediador. Renato Russo, ao indicar a leitura de Clarice, arrebata Sofia e a fisga. Ela ainda revela um espaço que a auxiliou na formação leitora, um sebo. Como toda apaixonada, Sofia revela-nos detalhes do momento que encontrou seu objeto de desejo [ $\mathscr{Z}$ apaixonada].

(32) O primeiro e, assim,... lembro até hoje o estranhamento quando eu comecei a ler Clarice Lispector. (NHOQUE, 2019, p. 124).

Para Barthes (2013), uma das funções da literatura é colocar o leitor em estado de perda, de estranhamento, de possibilitar a ele, a fruição. A experiência de encontro com a autora nos seus escritos provoca Sofia [ 2 Estranhamento].

(33) Porque eu vinha de leituras justamente... de traduções, de best-sellers, então, aquela leitura mais focada na narrativa, a linguagem mais linear, mais fluida. E eu peguei a primeira crônica, que se chama "Um Pintor", e li a primeira frase, que é "a surpresa de ver que o pintor começa por não recear, inclusive, a simetria", e eu falei "como essa mulher escreve mal". (NHOQUE, 2019, p. 124).

Diante do texto provocativo, o leitor pode aceitar o jogo e romper com a ilusão do texto legível. A identificação com o texto depende de variáveis que não possuem um padrão. Sofia revela estranheza pela forma do texto, muito diferente daquela que estava acostumada.

(34) Acredita, gente? Eu falei: "que 'inclusive'? Que frase é essa? Que coisa mal escrita?! Como é que o Renato Russo pode gostar disso? E eu fui folheando e cheguei numa outra crônica, que se chama "Sem Aviso", e ela vai... ela é bem pequenininha... eu vou ler, tá? (NHOQUE, 2019, p. 125).

Sofia tem um fetiche musical [o̊g̊ Música: Renato Russo], que diz gostar de uma escritora. Sofia não hesita em comprar o livro para conhecer mais o gosto do seu ídolo e questiona a escritura da autora [V desdém apaixonado]. Há um incômodo manifesto pela indicação de Renato Russo, pois inicialmente ela não consegue adentrar nos poros do texto, incômodo que se transforma em arrebatamento frente às descobertas que faz no processo de leitura. Em seguida, pede autorização ao grupo para compartilhar um fragmento do livro de Lispector (2010, p. 67-68).

(35) Que diz assim: "Tanta coisa que eu não sabia. Nunca tinham me falado, por exemplo, deste sol duro das três horas. Também não me tinham avisado sobre este ritmo tão seco de viver, desta martelada de poeira. Que doeria, tinham-me avisado. Mas o que vem para a minha esperança do horizonte, ao chegar perto se revela abrindo asas de águia sobre mim, isso eu não sabia. Não sabia o que é ser sombreada por grandes asas abertas e ameaçadoras, um agudo bico de águia inclinado sobre mim rindo". (NHOQUE, 2019, p. 125)

(36)E daí a frase que me pegou: "E quando nos álbuns de adolescente eu respondia com orgulho que não acreditava no amor, era então que eu mais amava; isso eu tive que aprender sozinha. Também não sabia no que dá mentir. Comecei a mentir por precaução, e ninguém me avisou do perigo de ser tão precavida; porque depois nunca mais a mentira descolou de mim. E tanto menti que comecei a mentir até a minha própria mentira. E isso - já atordoada eu sentia - isso era dizer a verdade. Até que decaí tanto que a mentira eu a dizia crua, simples, curta: eu dizia a verdade bruta." (NHOQUE, 2019, p. 125). 
Um fragmento escolhido para ser compartilhado, do livro que Sofia considera um marco na sua vida, quantos sentidos podem ser tirados dali. No entanto, vamos ficar com o que ela nos revela:

(37) Quando eu li essa frase, eu me vi nessa frase. E eu pensei assim: "Essa mulher sabe de coisas que ninguém mais sabe". Eu preciso ler. E daí foi onde se abriu para mim que, realmente, a literatura, ela não é só o plano narrativo, aquele que a professora Eleonora sempre fala para a gente nas aulas. Existem outras coisas sendo faladas ali. Existem outras coisas para você buscar. E se abriu esse universo, e daí foi onde eu fui atrás de Clarice e esse amor eterno por ela. (NHOQUE, 2019, p. 125).

Sofia reverbera sua paixão, paixão pelo livro, paixão pela autora e paixão pelas palavras da autora que conversam com sua vida. A leitura encarnada parece sair pelos poros do leitor, ela reverbera emoções contidas [ 2 Reconhecimento do desejo]. Um encontro com a leitura do literário que ressoa do que o leitor traz na alma [ $\bigcirc$ Enigma 7: (conclusão) leitura em que se reconhece].

Ao ser convidada a expressar suas últimas palavras daquele encontro, Sofia diz:

(38) Só que é bacana realmente falar sobre isso. Contar sobre a nossa experiência. (NHOQUE, 2019, p. 130).

Assim, Sofia aponta que aquele encontro entre participantes da pesquisa e a pesquisadora também foi um espaço de compartilhamento de afetos, de conhecimentos e de experiências e não só de coleta de dados. As narrativas de Sofia nos encaminham a compreender como fazer uma experiência a partir da leitura do literário repercute no leitor, amplia seus sentidos e o constitui um leitor encarnado. Essa compreensão foi sendo tecida por várias vozes que atestam a pluralidade do texto, lembrando-nos que as subjetividades e as intuiç̧ões não podem ser ignoradas na pesquisa científica.

\section{CONSIDERAÇÕES FINAIS}

Nosso objetivo foi exemplificar como a metodologia de análise progressiva desenvolvida por Barthes, a partir do conto Sarrasine, de Honoré de Balzac, pode ser utilizada também na análise de narrativas construídas em pesquisas científicas. Partimos do princípio de que pesquisas qualitativas, do campo das Ciências Sociais, sentem a necessidade de metodologias que resguardem a força expressiva contida nas narrativas dos sujeitos de pesquisa. Na Análise Progressiva das Narrativas, não são recortes da fala que são trazidos ao contexto da pesquisa para comprovar a hipótese traçada, pois tudo o que o sujeito de pesquisa narra aponta para uma percepção, um ponto de vista, que se soma a outros tantos para compor um grande mosaico intertextual.

As cinco vozes que emergem permitem-nos entrar por vários ângulos da narrativa, de modo a resguardar o princípio da reversibilidade que assevera a polissemia do texto, o plural de que é feito. Esse movimento faz-nos perceber que, nas pesquisas qualitativas desenvolvidas no campo das Ciências Sociais, 
não existe uma única forma de ler o texto e, por isso, a metodologia não pode imprimir um movimento de busca de algum significado final, determinado, mas, sim, propor um jogo lúdico que é realizado para multiplicar os significantes do texto que é lido.

O papel do pesquisador que adota essa metodologia é de um articulador, de um mediador que puxa vários fios que compõem essa teia verbal gigantesca, não para confirmar evidências, mas para suscitar questões. Uma metodologia que coloca em foco o processo de escuta do pesquisado e não tem compromisso com a infabilidade; por isso, tudo é socializado e passa pelo filtro da razão e da sensibilidade sem apartamentos; afinal, tudo é matéria vertente para a pesquisa.

A análise da narrativa de Sofia nos possibilita algumas inferências sobre o percurso de constituição de um leitor do literário:

- Em cada fase da vida o leitor tem algumas especificidades. No caso de Sofia, quando criança, seu interesse pela leitura foi motivado pelo desejo de estar junto a outros leitores da família. Ler foi um rito de passagem. Na adolescência, lia para compreender-se como pessoa e os anseios de fazer parte de um grupo social. Já, na vida adulta, reverberam as experiências do passado, e Sofia lê para estar junto, compartilhar leituras, descobertas e autoconhecimento.

- Sofia mostra-nos que as dificuldades na aprendizagem dos signos não impedem que alguém se torne leitor, pelo contrário, a leitura colabora na aprendizagem e a dificuldade pode ser um incentivador desde que haja um mediador de leitura que acompanhe.

- O papel do mediador é fundamental na constituição do leitor e não se fixa apenas em uma pessoa. Foi a autoridade reconhecida no pai que incentivou Sofia na infância; foram os livros oferecidos pela escola que a mantiveram desejosa por ler; foi a entrevista de um ídolo musical que Ihe apresentou Clarisse Lispector; foram os livros proibidos e desafiadores que a instigaram a ler mais.

- $\quad$ desejo e a curiosidade também permearam a relação de Sofia com a leitura do literário. Desejo de descobrir, curiosidade em entender. Sentimentos que estavam nela, mas foram incentivados, apoiados e valorizados por aqueles que estavam a sua volta.

A narrativa exitosa de Sofia em se constituir uma leitora do literário indica como a leitura pode promover a aproximação afetiva, o acolhimento e a inclusão das pessoas ao longo de sua vida e as diversas possibilidades no campo das Ciências da Educação na formação de leitores.

Entendemos que, ao tratarmos de formação de leitores, é importante considerarmos o contexto no qual esses leitores foram se constituindo, os mediadores de leitura que os circundaram, o tipo de leitura que lhes chegou às mãos e, principalmente, seus desejos e suas experiências. 


\section{REFERÊNCIAS}

ALMEIDA, Maria de Fátima Xavier da Anunciação de. O ensino de leitura literária nas vozes de professores de português recém-formados. 2016. 178 f. Tese (Doutorado em Letras) - Universidade Presbiteriana Mackenzie, São Paulo, 2016.

BARTHES, Roland. S/Z. Coleção Signo. Tradução Maria de Santana Cruz e Ana Mafalda Leite. Lisboa: Edições 70, 1999.

BARTHES, Roland. O prazer do texto. Tradução J. Guinsburg. 6. ed. São Paulo: Perspectiva, 20 I3.

BARTHES, Roland. O rumor da língua. Tradução Andréa Stahel M. da Silva. 3. ed. São Paulo: WMF Martins Fontes, 2012.

BLOG DO PROLIJ. Sobre o Prolij. 2017. Disponível em: http://blogdoprolij.blogspot.com.br/. Acesso em: 14 fev. 2018.

BRIDON, Janete. Entre um texto e outro, o leitor em formação. 20 I3. I6 | f. Dissertação (Mestrado em Educação) - Universidade do Vale do Itajaí, Itajaí, 2013.

ECO, Humberto. Ensaios sobre literatura. 2. ed. Tradução Elaine Aguiar. Rio de Janeiro: Record, 2003.

FLICK, Uwe. Entrevista Episódica. In: BAUER, Martin W.; GASKELL, George. (Orgs.). Pesquisa qualitativa com texto, imagem e som: um manual prático. 3. ed. . reimp. Tradução Pedrinho A. Guareschi. Petrópolis: Vozes, 2015. p. 114-136.

GADAMER, Hans-Georg. Verdade e método I: traços fundamentais de uma hermenêutica filosófica. I 5. ed. I. reimp. Tradução Flávio Paulo Meurer. Petrópolis: Vozes, 2016.

GASKELL, George. Entrevistas individuais e grupais. In: BAUER, Martin. W.; GASKELL, George. (Orgs.). Pesquisa qualitativa com texto, imagem e som: um manual prático. 3. ed. I. reimp. Tradução Pedrinho A. Guareschi. Petrópolis: Vozes, 2015. p. 64-89.

HEIDEGGER, Martin. Caminhos da linguagem. Tradução Marcia Sá Cavalcante Schuback. 5. ed. Petrópolis: Vozes; São Paulo: Editora Universitária São Francisco, 201 I .

JOVCHELOVITCH, Sandra; BAUER, Martin. W. Entrevista Narrativa. In: BAUER, Martin W.; GASKELL, George. (Orgs.). Pesquisa qualitativa com texto, imagem e som: um manual prático. 3. ed. I. reimp. Tradução Pedrinho A. Guareschi. Petrópolis: Vozes, 2015. p. 90-113.

LISPECTOR, Clarice. Crônicas Parágrafo Jovens: de amor e amizade. Organizado por Pedro Karp Vasquez. Rio de Janeiro: Rocco, 20 10. p. 67-68.

MANGUEL, Alberto. Os livros e os dias, um ano de leituras prazerosas. Tradução José Geraldo Couto. I. reimp. São Paulo: Companhia das Letras, 2005.

MINHAS TARDES com Margueritte. Direção de Jean Becker. Produção de Louis Becker e Gérard Depardieu. França: Imovision, 20 I0. I DVD (82 min), son., color.

NHOQUE, Janete Ribeiro. A leitura do literário como experiência. 2019. 3 I 4 f. Tese (Doutorado em Educação) - Universidade do Vale do Itajaí, Itajaí, 2019. 
OCTÁVIO, Raquel Gonçalves. Práticas de leitura entre leitores escolares e leitores contemporâneos: a ilusão do real. 20I4. 133 f. Tese (Doutorado em Educação) - Universidade Estadual de Campinas, Campinas, 2014.

OFFIAL, Patrícia Cesário Pereira. Formação de leitores do literário: uma experiência na Escola da Ponte. 20 I2. 134 f. Dissertação (Mestrado em Educação) - Universidade do Vale do Itajaí, Itajaí, 2012.

PETIT, Michèle. A arte de ler: ou como resistir à adversidade. 2. ed. I . reimp. Tradução Arthur Bueno e Camila Boldrini. São Paulo: 34, 2012.

PISKE, Gabriela. Encontros literários pela mediação em leitura. 20 I7. I 58 f. Dissertação (Mestrado em Educação) - Universidade do Vale do Itajaí, Itajaí, 2017.

TODOROV, Tzvetan. A literatura em perigo. Tradução Caio Meira. 3. ed. Rio de Janeiro: DIFEL, 2010.

VERTER, Lívia da Silva Perenha. Mediação de leitura do literário no Ensino Médio pela via fruitiva. 2019. 95 f. Dissertação (Mestrado em Educação) - Universidade do Vale do Itajaí, Itajaí, 20। 9.

WEISS, Cláudia Suéli. A leitura de literário e a sala de aula: mediações em/de leitura. 2016. 136 f. Dissertação (Mestrado em Educação) - Universidade do Vale do Itajaí, Itajaí, 2016. 